\title{
USING COMBINATION OF PLANAR AND HEIGHT FEATURES FOR DETECTING BUILT-UP AREAS FROM HIGH-RESOLUTION STEREO IMAGERY
}

\author{
Feifei Peng a,b, *, Xiaoyu Cai ${ }^{\mathrm{c}}$, Wenxia Tan ${ }^{\mathrm{a}, \mathrm{b}}$ \\ ${ }^{a}$ Key Laboratory for Geographical Process Analysis \& Simulation of Hubei Province, Central China Normal University, Wuhan \\ 430079, China - feifpeng@163.com; tanwenxia@mail.ccnu.edu.cn \\ ${ }^{\mathrm{b}}$ College of Urban and Environmental Sciences, Central China Normal University, Wuhan 430079, China \\ c Communication Technology Engineering Co., Ltd. of China Mobile Hubei branch, Wuhan 430010, China - \\ CXY1126710@163.com
}

KEY WORDS: Stereo Image, Built-up Area, Height Feature, Planar Feature, Multiple Features, DSM, DOM

\begin{abstract}
:
Within-class spectral variation and between-class spectral confusion in remotely sensed imagery degrades the performance of builtup area detection when using planar texture, shape, and spectral features. Terrain slope and building height are often used to optimize the results, but extracted from auxiliary data (e.g. LIDAR data, DSM). Moreover, the auxiliary data must be acquired around the same time as image acquisition. Otherwise, built-up area detection accuracy is affected. Stereo imagery incorporates both planar and height information unlike single remotely sensed images. Stereo imagery acquired by many satellites (e.g. Worldview-4, Pleiades-HR, ALOS-PRISM, and ZY-3) can be used as data source of identifying built-up areas. A new method of identifying highaccuracy built-up areas from stereo imagery is achieved by using a combination of planar and height features. The digital surface model (DSM) and digital orthophoto map (DOM) are first generated from stereo images. Then, height values of above-ground objects (e.g. buildings) are calculated from the DSM, and used to obtain raw built-up areas. Other raw built-up areas are obtained from the DOM using Pantex and Gabor, respectively. Final high-accuracy built-up area results are achieved from these raw built-up areas using the decision level fusion. Experimental results show that accurate built-up areas can be achieved from stereo imagery. The height information used in the proposed method is derived from stereo imagery itself, with no need to require auxiliary height data (e.g. LIDAR data). The proposed method is suitable for spaceborne and airborne stereo pairs and triplets.
\end{abstract}

\section{INTRODUCTION}

Accurately identifying built-up areas is an essential task for government agencies facing the complex and ever changing demands of city planning. Built-up areas are dynamic environments, and thus must be monitored periodically. Builtup areas have been identified from remotely sensed imagery, such as low- and moderate-resolution multispectral imagery, and high-resolution panchromatic imagery. A number of approaches for extracting built-up areas from remotely sensed imagery have been proposed using planar texture, shape, and spectral features, such as the Pantex index (Pesaresi et al., 2008), normalized difference built-up index (Xu, 2008), improved Harris corner (Tao et al., 2013), morphological differential attribute profile (Pesaresi et al., 2013), SIFT (Sirmacek and Unsalan, 2009), Gabor filters (Sirmacek and Unsalan, 2010), and vegetation indices (Graesser et al., 2012). Compared with low- and moderate-resolution spaceborne imagery, highresolution spaceborne imagery contains more detailed information for obtaining more granular and precise urban area identification results. In high-resolution spaceborne imagery, however, within-class spectral variation and between-class spectral confusion degrades the separability of various land use types (Yan et al., 2015). Built-up and not-built-up areas contain different land use types, and therefore the separability between them is also reduced. For instance, built-up areas comprised of large buildings with flat, single color roofs are likely to be identified as open space and misclassified as not-built-up areas.

The separability between urban and non-urban areas is increased by using height information. Height information is helpful for distinguishing among different land use types, since height is consistent within a class but varies between classes (Weng, 2012). Height information can significantly improve the classification performance for several classes, including residences, buildings, skyscrapers, trees, and open space, and thus increase the separability between them (Chen et al., 2015; Longbotham et al., 2012). Terrain slope and building height are used to optimize built-up identification results obtained with planar features (Miyazaki et al., 2013). However, these height features are usually extracted from auxiliary data (e.g. LIDAR data) (Duan et al., 2015; Zhang et al., 2014). The auxiliary data must be acquired around the same time as image acquisition. Otherwise, built-up area detection accuracy is affected.

Stereo imagery incorporates both planar and height information unlike single remotely sensed images. Moreover, stereo images are widely available. Stereo images are acquired by many satellites with stereo observation capabilities (Peng et al., 2015), such as IKONOS, Worldview-1 4, QuickBird, GeoEye-1, Cartosat-1/2, Pleiades-HR, ALOS-PRISM, and ZY3 satellites. A lot of stereo images are collected during a single overpass using standard simultaneous along-track systems, including the Cartosat-1, ALOS-PRISM, and ZY3 satellites. Spaceborne stereo imagery has a wide swath; such as, a 30-kilometer swath for Cartosat-1 images, and a 51-kilometer swath for ZY3 images. These stereo images cover the globe, and can be used as data source for many applications including built-up area identification (Gong et al., 2016). Planar and height features can be extracted from stereo images, and then are combined to achieve high-accuracy built-up areas.

* Corresponding author 


\section{METHODOLOGY}

The flowchart of identifying high-accuracy built-up areas from stereo imagery using a combination of planar and height features is shown as Figure 1. A digital surface model (DSM) is first produced from stereo imagery, and then used during producing a digital orthophoto map (DOM) from stereo imagery (Peng et al., 2016). Then, raw built-up areas are identified based on height values of nDSM (above-ground objects, e.g. buildings) obtained with a filter method from the DSM (Peng et al., 2016). Two raw built-up area identification results are obtained from the DOM by using the Pantex method (Pesaresi et al., 2008), and the Gabor method (Sirmacek and Unsalan, 2010), respectively. The intersection of the two results is seen as one candidate of final built-up areas. Another candidate of final built-up areas is the intersection of the raw result achieved using the DSM method and the union of the two raw results achieved from DOM. The union of the two candidates is used as the final built-up area result. Finally, the accuracy of the built-up area identification result is assessed. The true-positive rate, falsealarm rate, and kappa coefficient (Tao et al., 2013) are used in our study.

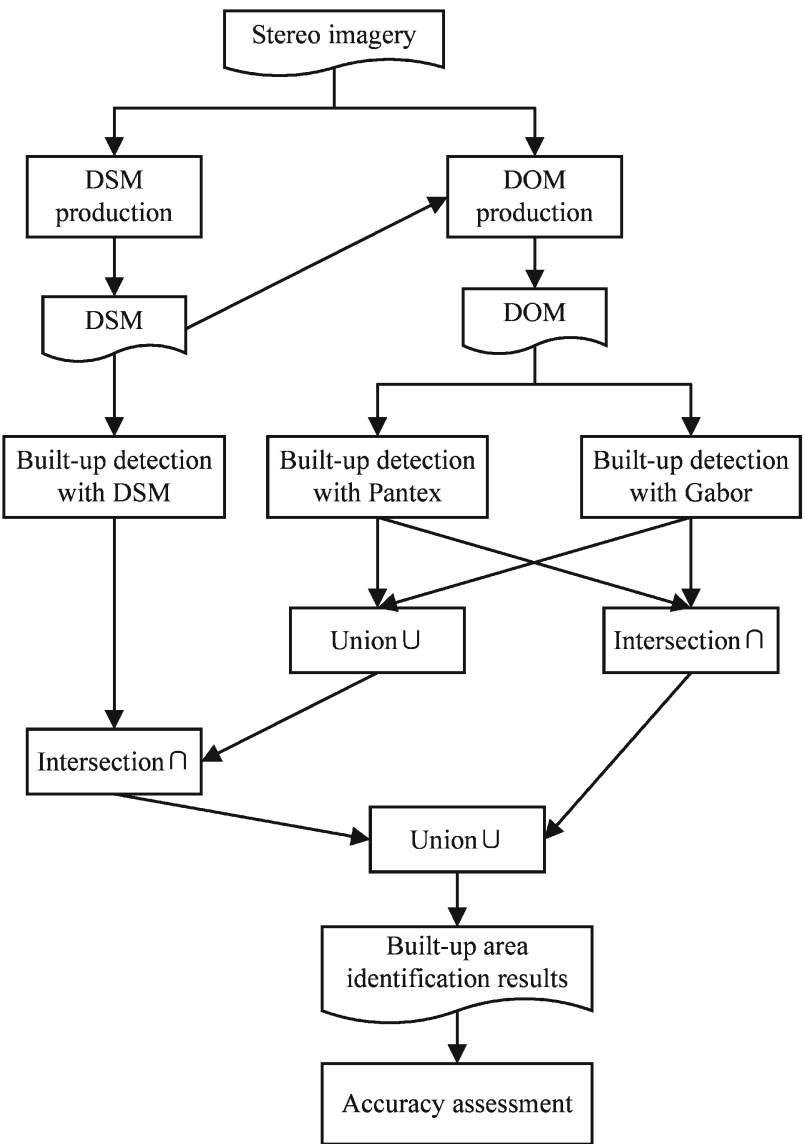

Figure 2. Flowchart of our method to detect built-up areas from stereo imagery.

\section{EXPERIMENTAL RESULTS}

\subsection{Study Data}

Figure 2 shows the two stereo pairs used in our experiments. The stereo pair 1 was acquired by the Pleiades-1A sensor on February 25, 2012, and covers a scene located in Williamstown, Melbourne, Australia. The stereo pair 2 was acquired by the Worldview-1 sensor on August 29, 2008, and covers a scene located in Terrassa, Catalonia, Spain. They have panchromatic bands alone. Their characteristics are shown in Table 1.

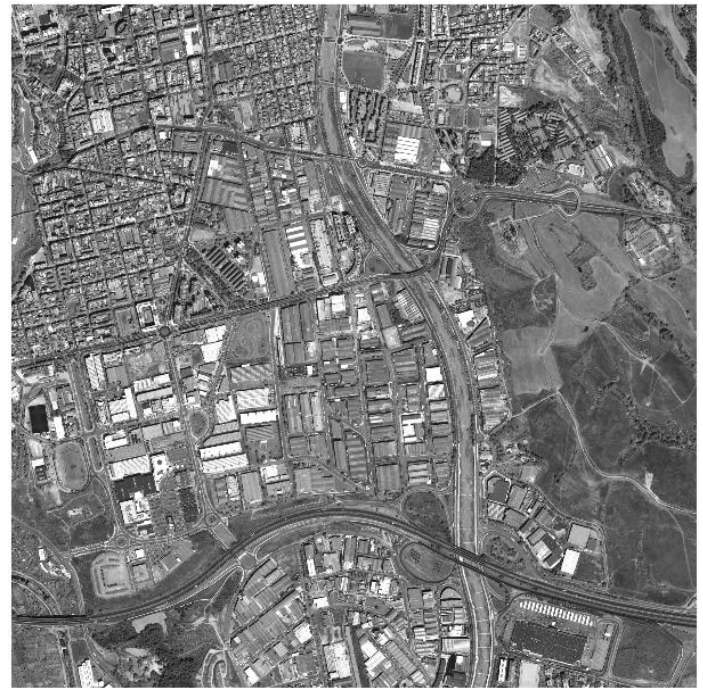

(a)

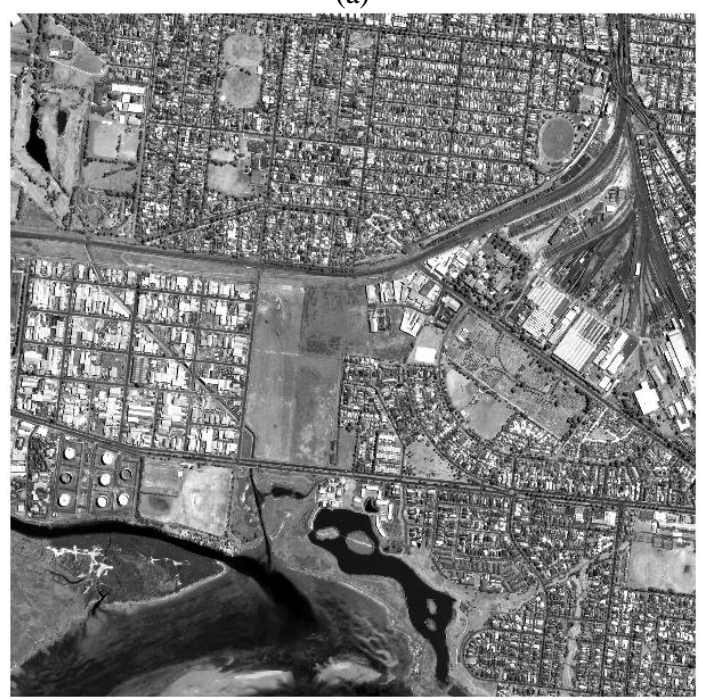

(b)

Figure 2. Two stereo pairs used in our experiments.

\begin{tabular}{|c|c|c|c|c|}
\hline \multirow{2}{*}{ Characteristics } & \multicolumn{2}{|c|}{ Stereo pair 1 } & \multicolumn{2}{c|}{ Stereo pair 2 } \\
\cline { 2 - 5 } & Image 1 & Image 2 & Image 1 & Image 2 \\
\hline Acquisition time & $00: 25: 32$ & $00: 26: 27$ & $10: 51: 12$ & $10: 50: 27$ \\
\hline $\begin{array}{c}\text { Radiometric } \\
\text { resolution }\end{array}$ & 8 bits & 8 bits & 11 bits & 11 bits \\
\hline $\begin{array}{c}\text { Ground sample } \\
\text { distance (GSD) }\end{array}$ & $0.5 \mathrm{~m}$ & $0.5 \mathrm{~m}$ & $0.51 \mathrm{~m}$ & $0.66 \mathrm{~m}$ \\
\hline Sun azimuth & $54.0^{\circ}$ & $53.7^{\circ}$ & $152.8^{\circ}$ & $152.5^{\circ}$ \\
\hline Sun elevation & $49.6^{\circ}$ & $49.7^{\circ}$ & $55.0^{\circ}$ & $54.9^{\circ}$ \\
\hline Satellite azimuth & $2.7^{\circ}$ & $185.0^{\circ}$ & $256.2^{\circ}$ & $7.6^{\circ}$ \\
\hline Satellite elevation & $73.9^{\circ}$ & $73.8^{\circ}$ & $85.9^{\circ}$ & $55.0^{\circ}$ \\
\hline Off-nadir view angle & $16.2^{\circ}$ & $16.5^{\circ}$ & $4^{\circ}$ & $33^{\circ}$ \\
\hline Convergence angle & $32.3^{\circ}$ & \multicolumn{2}{c|}{$36.7^{\circ}$} \\
\hline Base-height-ratio & \multicolumn{2}{|c|}{0.57} & \multicolumn{3}{c|}{0.77} \\
\hline
\end{tabular}

Table 1. Characteristics of two stereo pairs. 


\subsection{Built-up area identification results}

The built-up area identification results from the two stereo pairs are shown in Figures 3-4, respectively. The result obtained from the DOM using the Pantex method differed with that using the Gabor method. The built-up area result obtained from the DSM contained some false-alarm areas, which were often areas including a lot of high trees, such as in subfigure (c) of Figures 3-4. As seen in subfigure (d) of Figures 3-4, the result obtained with a combination of planar and height features using our method had higher accuracy. Moreover, our method identified complete built-up areas, while other three methods often obtained fragmentary built-up areas.

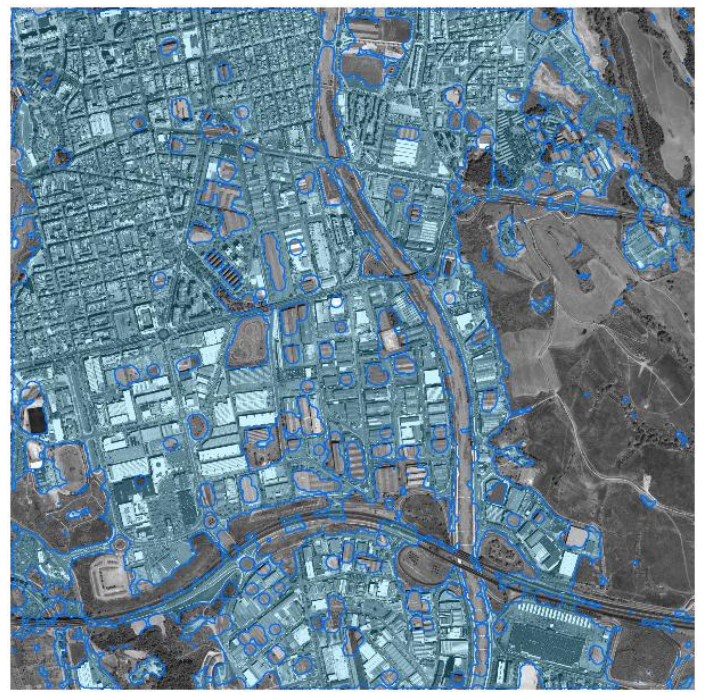

(a)

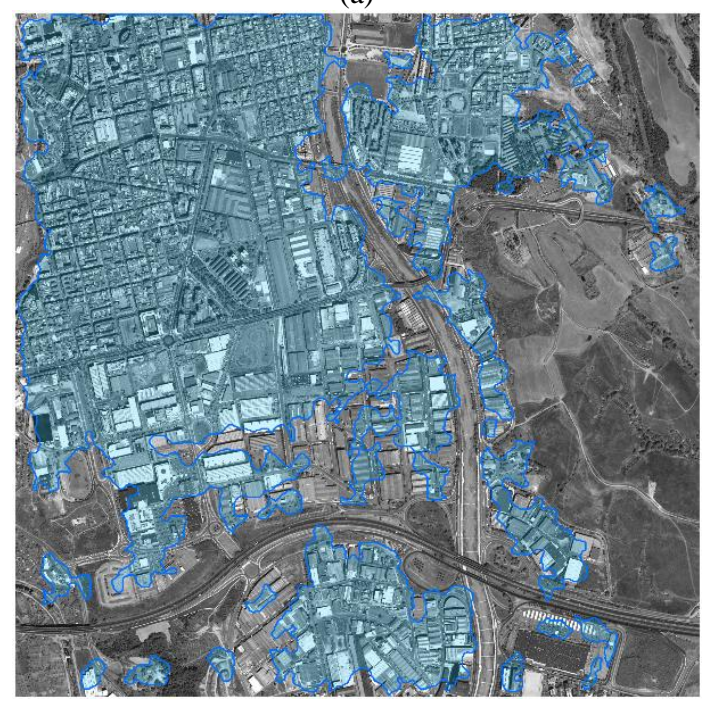

(b)

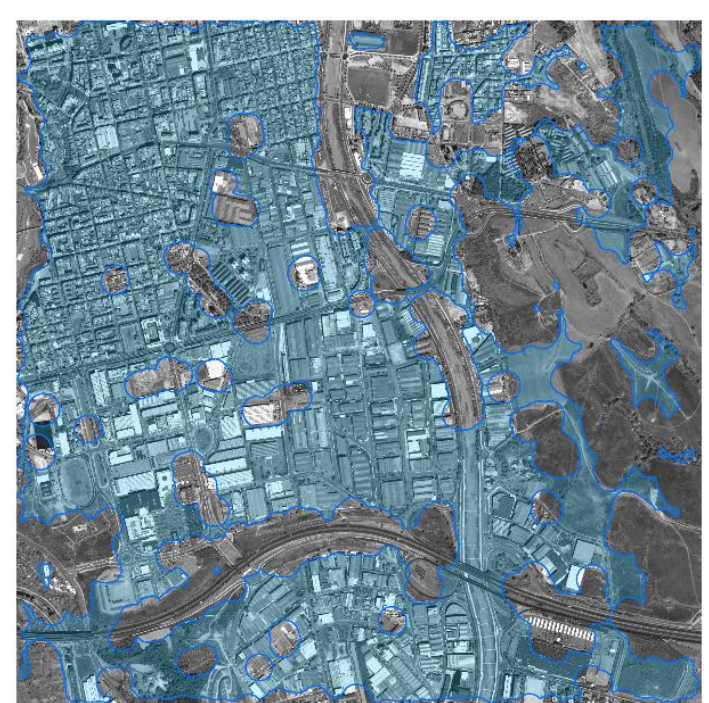

(c)

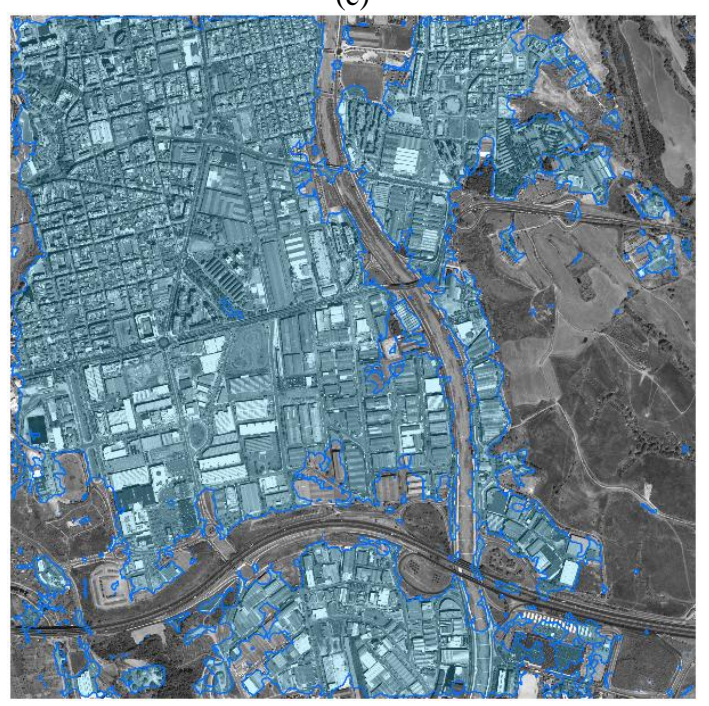

(d)

Figure 3. Results for Stereo pair 1 obtained using different built-up area detection methods. (a) Pantex method. (b) Gabor method. (c) nDSM method. (d) Our method.

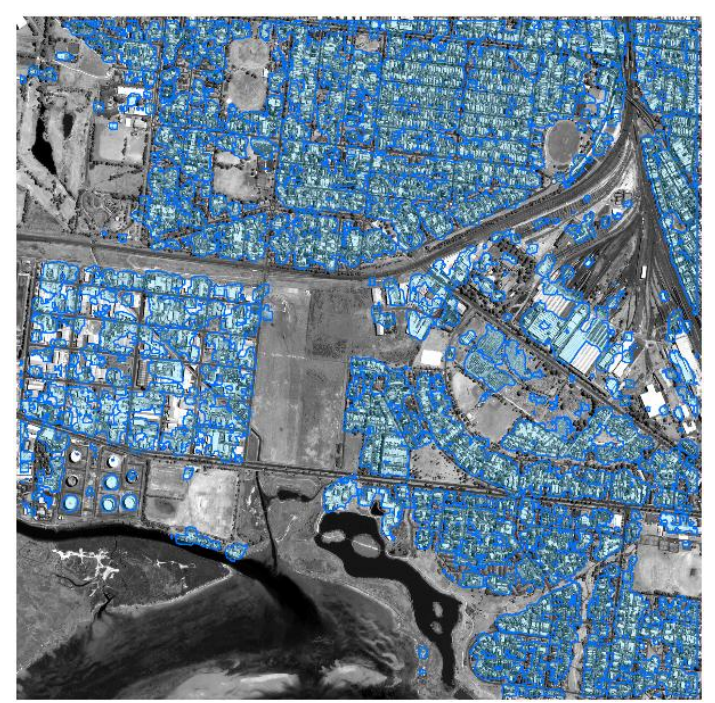

(a) 


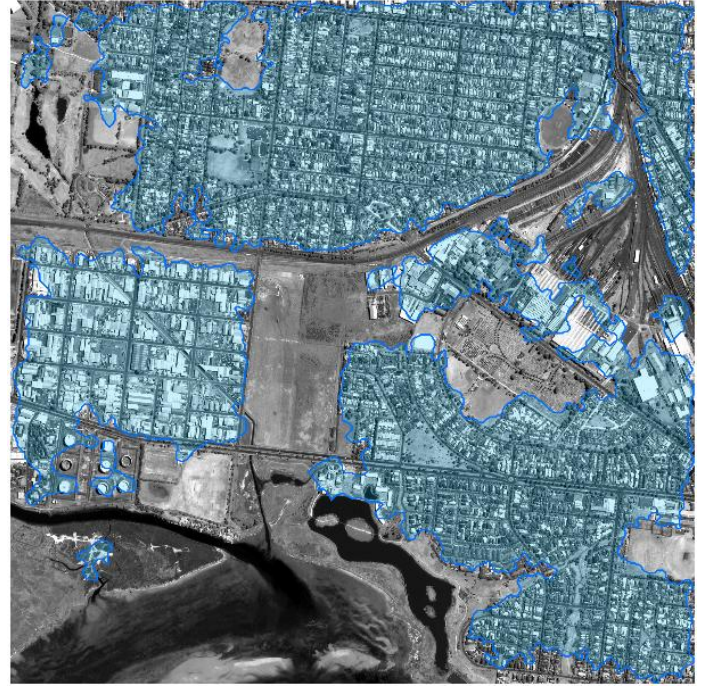

(b)

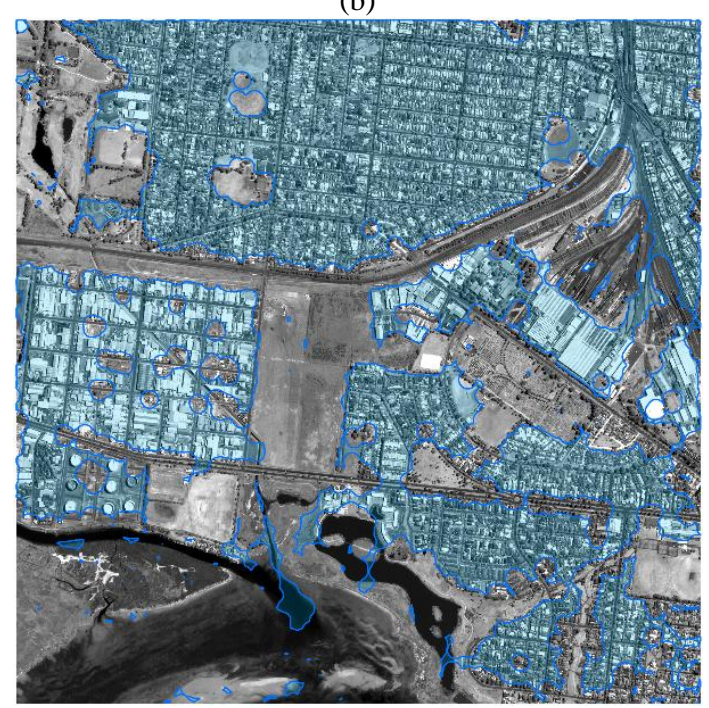

(c)

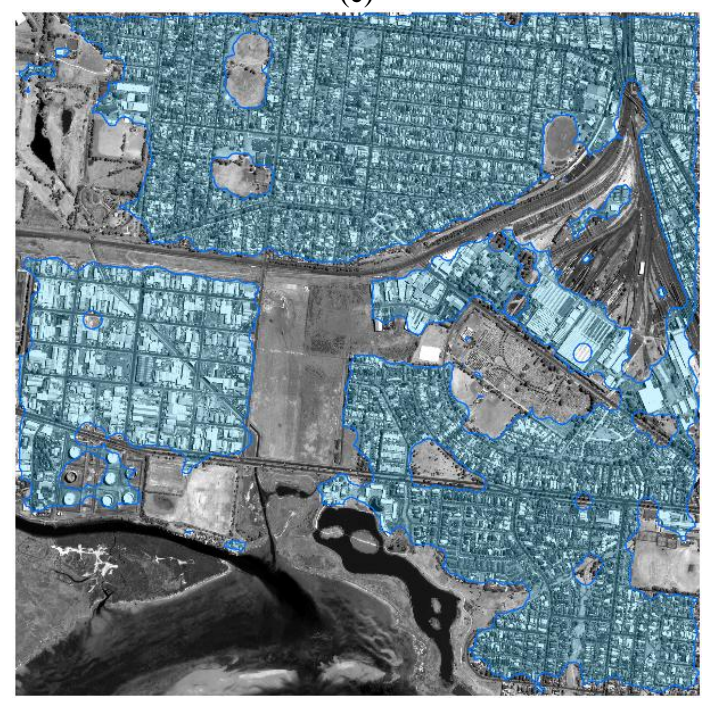

(d)

Figure 4. Results for Stereo pair 2 obtained using different built-up area detection methods. (a) Pantex method. (b) Gabor method. (c) nDSM method. (d) Our method.

\subsection{Built-up area identification result accuracy}

Table 2 shows accuracy of built-up area identification results of the two stereo pairs. For both the two stereo pairs, our method improved the true-positive rate, and kappa coefficient, and achieved lower false-alarm rate in comparison to other three methods using one feature alone. For the stereo pair 1, our method achieved a litter higher false-alarm rate than the Gabor method (0.03); however, the false-alarm rate of our method was still very low (0.04). In addition, the accuracy in stereo pair 1 was higher than the accuracy in stereo pair 2.

\begin{tabular}{|c|c|c|c|c|c|}
\hline \multicolumn{2}{|c|}{ Accuracy } & $\begin{array}{l}\text { Pantex } \\
\text { method }\end{array}$ & $\begin{array}{l}\text { Gabor } \\
\text { method }\end{array}$ & $\begin{array}{l}\mathrm{nDSM} \\
\text { method }\end{array}$ & $\begin{array}{c}\text { Our } \\
\text { method }\end{array}$ \\
\hline \multirow{3}{*}{$\begin{array}{l}\text { Stereo } \\
\text { pair } 1\end{array}$} & $\begin{array}{l}\text { true-positive } \\
\text { rate }\end{array}$ & 0.77 & 0.69 & 0.71 & 0.79 \\
\hline & $\begin{array}{l}\text { false-alarm } \\
\text { rate }\end{array}$ & 0.09 & 0.03 & 0.18 & 0.04 \\
\hline & $\begin{array}{c}\text { kappa } \\
\text { coefficient }\end{array}$ & 0.82 & 0.79 & 0.74 & 0.85 \\
\hline \multirow{3}{*}{$\begin{array}{l}\text { Stereo } \\
\text { pair } 2\end{array}$} & $\begin{array}{l}\text { true-positive } \\
\text { rate }\end{array}$ & 0.52 & 0.75 & 0.70 & 0.76 \\
\hline & $\begin{array}{l}\text { false-alarm } \\
\text { rate }\end{array}$ & 0.01 & 0.02 & 0.04 & 0.01 \\
\hline & $\begin{array}{c}\text { kappa } \\
\text { coefficient }\end{array}$ & 0.41 & 0.63 & 0.55 & 0.66 \\
\hline
\end{tabular}

Table 2. Accuracy results of two stereo pairs.

\section{CONCLUSION}

A new method of identifying high-accuracy built-up areas from stereo imagery is achieved by using a combination of planar and height features in the decision level fusion. These planar and height features are respectively extracted from the digital surface model (DSM) and digital orthophoto map (DOM) generated from stereo images. Experimental results show that accurate built-up areas can be achieved from stereo imagery. The proposed method is not affected by the within-class spectral variation and between-class spectral confusion in remotely sensed imagery, which degrade the performance of built-up area detection when using planar texture, shape, and spectral features. Moreover, the height information used in the proposed method is derived from stereo imagery itself, with no need to require auxiliary height data (e.g. LIDAR data). Our method is suitable for both spaceborne and airborne stereo images. Our method is suitable for stereo triplets as well as stereo pairs.

\section{ACKNOWLEDGMENT}

This work was supported by the National Science Foundation of China under Grant 41701511, the Hubei Provincial Natural Science Foundation of China (Program ID: ZRMS2017001155, Name: "High-resolution Stereo Image Retrieval With Both Height and Planar Features"), the Open Research Fund of State Key Laboratory of Information Engineering in Surveying, Mapping and Remote Sensing under Grant 16E03, and the Selfdetermined Research Funds of CCNU from the Colleges' Basic Research and Operation of MOE under Grant CCNU16A05048. Special thanks are given to the data providers for the provision of the stereo datasets: Airbus Defense and Space for the Pleiades-1A imagery, and Digital Globe for the Worldview-1 imagery. 


\section{REFERENCES}

Chen, J., Chen, J., Liao, A., Cao, X., Chen, L., Chen, X., He, C., Han, G., Peng, S., Lu, M., Zhang, W., Tong, X., Mills, J., 2015. Global land cover mapping at $30 \mathrm{~m}$ resolution: A POK-based operational approach. ISPRS J. Photogramm. Remote Sens. 103 $7-27$.

Duan, Y., Shao, X., Shi, Y., Miyazaki, H., Iwao, K., Shibasaki, R., 2015. Unsupervised Global Urban Area Mapping via Automatic Labeling from ASTER and PALSAR Satellite Images. Remote Sens. 7, 2171-2192.

Gong, J., Peng, F., Wang, L., Wu, H., 2016. Built-up Area Detection from a Stereo Pair Using Disparity Information. Geomatics and Information Science of Wuhan University 41, 427-433.

Graesser, J., Cheriyadat, A., Vatsavai, R.R., Chandola, V., Long, J., Bright, E., 2012. Image Based Characterization of Formal and Informal Neighborhoods in an Urban Landscape. IEEE J. Sel. Topics Appl. Earth Observ. Remote Sens. 5, 1164-1176.

Longbotham, N., Chaapel, C., Bleiler, L., Padwick, C., Emery, W.J., Pacifici, F., 2012. Very High Resolution Multiangle Urban Classification Analysis. IEEE Trans. Geosci. Remote Sens. 50, 1155-1170.

Miyazaki, H., Xiaowei, S., Iwao, K., Shibasaki, R., 2013. An Automated Method for Global Urban Area Mapping by Integrating ASTER Satellite Images and GIS Data. IEEE J. Sel. Topics Appl. Earth Observ. Remote Sens. 6, 1004-1019.

Peng, F., Gong, J., Wang, L., Wu, H., Yang, J., 2016. Impact of Building Heights on 3d Urban Density Estimation from Spaceborne Stereo Imagery. Int. Arch. Photogramm. Remote Sens. Spatial Inf. Sci. XLI-B3, 677-683.

Peng, F., Wang, L., Gong, J., Wu, H., 2015. Development of a Framework for Stereo Image Retrieval With Both Height and Planar Features. IEEE J. Sel. Topics Appl. Earth Observ. Remote Sens. 8, 800-815.

Pesaresi, M., Gerhardinger, A., Kayitakire, F., 2008. A Robust Built-Up Area Presence Index by Anisotropic RotationInvariant Textural Measure. IEEE J. Sel. Topics Appl. Earth Observ. Remote Sens. 1, 180-192.

Pesaresi, M., Huadong, G., Blaes, X., Ehrlich, D., Ferri, S., Gueguen, L., Halkia, M., Kauffmann, M., Kemper, T., Lu, L., Marin-Herrera, M.A., Ouzounis, G.K., Scavazzon, M., Soille, P., Syrris, V., Zanchetta, L., 2013. A Global Human Settlement Layer From Optical HR/VHR RS Data: Concept and First Results. IEEE J. Sel. Topics Appl. Earth Observ. Remote Sens. 6, 2102-2131.

Sirmacek, B., Unsalan, C., 2009. Urban-Area and Building Detection Using SIFT Keypoints and Graph Theory. IEEE Trans. Geosci. Remote Sens. 47, 1156-1167.

Sirmacek, B., Unsalan, C., 2010. Urban Area Detection Using Local Feature Points and Spatial Voting. IEEE Geosci. Remote Sens. Lett. 7, 146-150.

Tao, C., Tan, Y., Zou, Z.-r., Tian, J., 2013. Unsupervised Detection of Built-Up Areas From Multiple High-Resolution Remote Sensing Images. IEEE Geosci. Remote Sens. Lett. 10, 1300-1304.
Weng, Q., 2012. Remote sensing of impervious surfaces in the urban areas: Requirements, methods, and trends. Remote Sensing of Environment 117, 34-49.

$\mathrm{Xu}, \mathrm{H} ., 2008$. A new index for delineating built - up land features in satellite imagery. Int. J. Remote Sens. 29, 4269-4276.

Yan, W.Y., Shaker, A., El-Ashmawy, N., 2015. Urban land cover classification using airborne LiDAR data: A review. Remote Sens. Environ. 158, 295-310.

Zhang, J., Li, P., Wang, J., 2014. Urban Built-Up Area Extraction from Landsat TM/ETM+ Images Using Spectral Information and Multivariate Texture. Remote Sens. 6, 73397559 . 